\title{
History of Canadian Anaesthesia
}

\section{David Campbell Aikenhead (1891-1973)}

That anaesthesia in Montréal and Toronto early in the 20 th century should have developed as rapidly as in leading American and British centres is not surprising, but its successful development elsewhere in so vast and sparsely populated a country as Canada makes us respect those pioneer anaesthetists who worked in smaller centres. Webster in Winnipeg, Muir in Halifax, Leech in Regina and Freeze in Vancouver were such a breed. Another was David Campbell Aikenhead, another Winnipeg anaesthetist.

Aikenhead was born in Hartney, Manitoba, on July 13, 1891. After schooling in Hartney and Melita, he enrolled in Manitoba Medical College in 1912. His thirdyear studies were interrupted by service with the Royal Canadian Army Medical Corps in England and France in 1915 and 1916, but he then returned to complete his medical studies - only to serve in France again for the remainder of the war. He set up general practice in Sinclair, Manitoba, in 1919, but his interest in anaesthesia led him to join the department of anaesthesia at the Winnipeg General Hospital (headed by William Webster) in 1920.

For several years, like many anaesthetists of that era, Aikenhead combined anaesthesia with general practice. However, as the need grew for competent anaesthesia and physicians with a special interest in anaesthesia, so he gave more and more of his time to anaesthesia. By 1935, when Webster died, Aikenhead was ready to take over the headship of the Winnipeg department, and he remained in this position until 1953, when he left for Hamilton and, later, Burlington. He retired from practice in 1969.

Aikenhead practised in exciting years for anaesthetists. New drugs (ethylene, cyclopropane, thiopentone, dtubocurarine and, later, other relaxants and the fluorinated volatile agents) and new techniques (endotracheal intubation, carbon dioxide absorption and controlled ventilation) gave anaesthetists previously unknown control of the pharmacological and physiological bases of anaesthesia. Always forward-thinking, Aikenhead welcomed these advances and introduced them to Winnipeg. Membership in the select Anaesthetists' Travel Club gave him knowledge and authority, and he used these to advance anaesthesia in Winnipeg. He developed the department there, stimulated educational activities among his colleagues and initiated meetings from which emerged the Winnipeg Anaesthetists' Society. As well, he put the teaching of students, interns and residents on a firm footing.

Aikenhead's academic interests led him to conduct two reviews of large series of anaesthetics. The first review, published in 1922, was a study of 7000 anaesthetics. The common agents were ether, chloroform and ethyl chloride. The former two were given by open drop onto a stockinette-covered Gwathmey mask; the last, by either a closed Ormsby inhaler or a Gwathmey mask with a spray and drip technique. Oxygen and a metal airway were used when necessary. Respiratory complications were emphasized for they were fatal in four patients. The second review, published in 1940, was based on a series of 3549 anaesthetics. Ether, now given by the semi-closed method, constituted almost half of them; cyclopropane was the agent in just under one third; and a "spinal" anaesthetic was administered in a little under one-fifth of the cases. By this time the use of the endotracheal tube was relatively (but still not very) common, being part of the technique in anaesthesia for 300 patients undergoing abdominal operations.

Quietly but steadily, Aikenhead became well known and respected in both anaesthesia and medical circles. He was a member of the Council of the Canadian Anaesthetists' Society from 1943 to 1947, and he was president of the Manitoba Medical Association from 1943 to 1944.

David Aikenhead was one of those individuals whose presence made a difference to those around him, whether these were his patients, his colleagues, hospital employees or members of his community. He was wise, humane and kind. Excellence came naturally to him, and Canadian anaesthetists have reason to admire his pioneering achievements, which did much to lay a path for others to follow.

David A.E. Shephard 